\title{
Retrospective lifetime dietary patterns are associated with demographic and cardiovascular health variables in an older community-dwelling Australian population
}

\author{
Diane Hosking ${ }^{1,2 *}$ and Vanessa Danthiir ${ }^{2}$ \\ ${ }^{1}$ School of Psychology, University of Adelaide, South Australia, Australia \\ ${ }^{2}$ CSIRO Animal, Food and Health Sciences, Preventative Health Flagship, PO Box 10041, \\ Adelaide, South Australia 5000, Australia \\ (Submitted 25 May 2012 - Final revision received 4 April 2013 - Accepted 8 April 2013 - First published online 3 June 2013)
}

\section{Abstract}

Dietary patterns derived from factor analytic procedures have been demonstrated to predict demographic and health outcomes across a wide range of populations. To examine the potential utility of long-term dietary recall, in the present study, we examined associations between dietary patterns from across the lifespan and demographic and later-life cardiovascular-related health variables, using the Lifetime Diet Questionnaire (LDQ). The LDQ is a self-administered, non-quantitative, retrospective FFQ designed to assess dietary intake from childhood to older age. Participants ( $n$ 352) from the Older People, Omega-3 and Cognitive Health trial, aged 65-91 years, completed the LDQ. Exploratory factor analysis was conducted on the LDQ and plausible dietary patterns were derived. As a result, three patterns were extracted from each life period, with five distinct patterns overall; these were 'traditional Australian' and 'non-traditional Australian', 'high-sugar and high-fat', 'vegetable' and 'fruit and vegetable' patterns. In separate adjusted regression models, age, sex, education, income, parental background and childhood physical activity all significantly predicted dietary patterns across the lifespan. A 'traditional Australian' pattern in childhood predicted higher HDL-cholesterol levels and lower odds of cholesterol medication use; lower HDL-cholesterol levels were predicted by the adult 'processed, high-sugar and high-fat' pattern, and higher intake of a 'non-traditional Australian' pattern in adulthood also predicted lower odds of using cardiac medications. Lifetime dietary recall, as instantiated by the LDQ, provides a hitherto untapped source of long-term dietary information in older adults that may contribute to greater understanding of the impact exerted by early-life and cumulative dietary choices on later-life health.

Key words: Lifetime Diet Questionnaire: Long-term dietary recalls: Dietary patterns: Cardiovascular health

With the increase in lifespan, healthy ageing has become a public health priority. The World Health Organization's 2002 Active Ageing Report $^{(1)}$ has recommended a life-course approach to older-age health and well-being that acknowledges the critical periods throughout life when an individual may be particularly vulnerable to environmental exposures and the cumulative effect of these environmental influences that may interact with genetic propensity to health or disease ${ }^{(2,3)}$.

Dietary intake has been identified as one of the readily modifiable environmental factors that influence health, in particular intake levels of antioxidant vitamins and minerals and nutrients such as folate, vitamin $\mathrm{B}_{12}, n-3$ fats and dietary fibre $^{(4)}$. Recently, there has been increasing interest in analysing dietary intake in terms of whole dietary patterns, given that individual nutrients or even foods are not eaten in isolation and may act in a synergistic manner to influence outcomes $^{(5,6)}$. Dietary patterns may be defined by two general approaches. In the first approach, dietary intake indices or scores group together foods and nutrients that are associated with health or other outcomes ${ }^{(7)}$. Diets are assessed for the presence or absence of the relevant foods/nutrients and the scores indicate the level of adherence to the a priori defined dietary pattern ${ }^{(6)}$, for example the Healthy Eating Index developed by the US Department of Agriculture ${ }^{(8)}$ and the Mediterranean Diet Score ${ }^{(9)}$. The second approach is driven by the statistical relationships between dietary variables and is not dependent on the pre-existing definitions of diet quality, although theoretical interpretability is an important consideration when evaluating the patterns that emerge from the data $^{(7)}$. These methods generally derive dietary patterns that

Abbreviations: CCFFQ, Cancer Council FFQ; CSIRO, Commonwealth Scientific and Industrial Research Organisation; EFA, exploratory factor analysis; EPOCH, Older People, Omega-3 and Cognitive Health; LDQ, Lifetime Diet Questionnaire.

*Corresponding author: D. Hosking, fax +61 83038899 , email diane.hosking@csiro.au 
are specific to a particular population; nonetheless, common patterns such as 'healthy', 'traditional', 'sweets' and 'Western' patterns have emerged consistently across studies ${ }^{(10)}$. Cluster analysis, factor analysis and principal component analysis all fall into this category of data-driven methodology ${ }^{(7)}$.

Although there is some theoretical and methodological debate surrounding the objectivity and reproducibility of dietary patterns ${ }^{(6,7,11,12)}$, the approach is nonetheless considered a valuable exploratory tool in nutritional epidemiology ${ }^{(13)}$. Instantiations of both healthy and unhealthy dietary patterns have been associated with older-age disease risk factors such as hypertension, cholesterol levels and BMI measurements ${ }^{(14,15)}$ and with the risk of developing $\mathrm{CVD}^{(16)}$, cancer ${ }^{(17)}$, diabetes $^{(18,19)}$, Alzheimer's disease and cognitive decline ${ }^{(20,21)}$, as well as with all-cause mortality ${ }^{(22-25)}$. Furthermore, it has been recognised that dietary patterns are determined within the context of the broader sociodemographic environments of the population under consideration; age, sex, ethnicity, education and occupation have all been shown to influence the consumption of particular dietary patterns. Such information can enable the identification of those groups that would benefit from public health initiatives regarding dietary intake ${ }^{(26-29)}$.

Given the demonstrated relationships between dietary patterns and disease risk, together with the salience of a lifecourse perspective on healthy ageing ${ }^{(3,30)}$, assessing dietary patterns from across the lifespan could contribute valuably to our understanding of long-term dietary influence on older-age health outcomes. However, accruing actual lifetime dietary data requires longitudinal cohort studies and these are relatively rare; in those that do exist, the comprehensive biological and psychosocial data necessary for life-course research were not collected always or even available ${ }^{(3,31)}$. Thus, despite the plausible influence of earlier-life dietary intake on later-life health, dietary assessment across multiple life periods remains a considerable research challenge. An alternative approach to logistically complex and costly longitudinal cohort studies, when investigating the contribution of lifetime diet to older-age outcomes, is to use the recall of lifetime diet from cognitively healthy older adults ${ }^{(32)}$.

Although measurement error is inherent in past diet recall, it may have some utility in dietary epidemiology ${ }^{(33,34)}$, in particular on a group level when the reported intake level, either low or high, is used to predict disease outcomes ${ }^{(34)}$. Recently, the Lifetime Diet Questionnaire (LDQ), a nonquantitative, retrospective lifetime FFQ, has been proposed as an instrument to assess lifetime diet in older people. It has been shown to have excellent test-retest reliability in an older cognitively healthy sample, with an average reproducibility correlation coefficient of 0.81 for the recall of dietary intake across five life periods ${ }^{(32)}$. One method of examining the potential utility of the LDQ as an instrument to examine relationships between older-age health outcomes and dietary intake from across the lifespan is to first extract plausible dietary patterns from the LDQ and then relate these to outcomes. To this end, the present study conducted an exploratory factor analysis (EFA) of the items from the LDQ. Subsequently, associations were investigated between these LDQ factors and current demographic and cardiovascular health variables.

\section{Methods}

\section{Participants}

Participants were drawn from the Older People, Omega-3 and Cognitive Health (EPOCH) cohort, who participated in an 18-month randomised controlled trial assessing the effects of $n$-3 fish oil on cognitive functioning in a cognitively healthy, community-dwelling population of older adults in Adelaide, South Australia( ${ }^{(35)}$. The present study was conducted according to the guidelines laid down in the Declaration of Helsinki, and all procedures involving human subjects were approved by the Commonwealth Scientific and Industrial Research Organisation (CSIRO) Human Ethics Committee. Written informed consent was obtained from all subjects. A total of 352 subjects $(53.7 \%$ female) completed the LDQ, aged in the range of 65-91 years (mean $73 \cdot 12$ (SD 5.47) years). Of the total participants, $26.4 \%$ of men and $37.6 \%$ of women completed schooling to year 10 and $22 \cdot 7 \%$ of men and $21.8 \%$ of women completed schooling to year 12 . A bachelor or higher degree was held by $8.2 \%$ of the sample. Median gross household income accorded with the national median for individuals aged 65 years and above ${ }^{(36)}$. For $95 \%$ of the participants, English was the first language, but $13 \%$ had at least one parent from a non-Anglo background. The baseline Mini Mental State Examination ${ }^{(37)}$ mean score for the LDQ cohort was 28.71 (SD 1.32).

Mann-Whitney non-parametric tests demonstrated that there were no significant differences between LDQ participants and non-participants from the EPOCH cohort in age, level of education and baseline Mini Mental State Examination score.

\section{Lifetime diet assessment}

The LDQ is a self-reported, non-quantitative FFQ that divides the life into periods of 15 years from childhood until older age. The questionnaire has been described previously ${ }^{(32)}$, but a brief overview is given: participants recalled their average consumption frequency of various food items on a four-point frequency scale ranging from 'rarely/never' to 'daily'. The food groups and their items were the same for each life period, with exceptions being food items that were unlikely to have been consumed during a particular life period, specifically alcohol-related questions for childhood and those related to lard for the later-life periods. The number of items for each life period ranged from seventyfour in childhood to seventy-nine in early adulthood, with adulthood and middle age each having seventy-eight items. Questions assessing physical activity levels were also asked as a proxy measure for energy expenditure across each life period. One question was asked for each life period regarding the frequency per week of vigorous, moderate and light physical activities. One additional question (for all periods except for childhood) was included to determine the physical activity level ('little, some, frequent, or heavy and frequent') associated with occupation. Recall across life periods was aided by a series of autobiographical cue questions that were completed before the period-specific dietary recall 
questions; these were related to family and working lives at the time as well as to important world or personal events that may have occurred.

The LDQ has been shown to have good reproducibility in an older population with test-retest correlations for each of the life-period questionnaires being 0.86 for childhood, 0.81 for early adulthood, 0.82 for adulthood, 0.79 for middle age and 0.80 for older age. The average-weighted $\kappa$ statistics for food items between the two administrations of the questionnaire were 0.55 for childhood, 0.36 for early adulthood, 0.52 for adulthood, 0.051 for middle age and 0.53 for older age ${ }^{(32)}$.

\section{Current diet}

Current diet was assessed by the Victorian Cancer Council FFQ $(\mathrm{CCFFQ})^{(38)}$, an eighty-four-item assessment of dietary intake over the previous 12 months. Response frequencies ranged from 1 ('never') to 10 ('three or more times a day') with the exception of eggs (number per week) and bread, milk and sugar, for which responses were defined as units per $\mathrm{d}$.

Reported current intake was used in subsequent analyses to control for the known influence of current diet recall on past diet recall ${ }^{(39)}$. To ensure that current intake was represented in a manner commensurate with past intake, foods that were assessed by the CCFFQ but not by the LDQ were excluded (eighteen items). In addition, consumption frequencies of the relevant items were converted to equivalent times per week, and composite items were made from some individual foods to represent the food groupings in the LDQ; for example, the items cabbage, broccoli and cauliflower in the CCFFQ were combined into a single item 'cruciferous vegetables' and bacon, ham, sausages and salami in the CCFFQ were combined to form 'processed meats', as represented in the LDQ.

\section{Demographic and cardiovascular health variables}

Extensive health and demographic information was collected from the EPOCH cohort, which has been fully described in the study protocol ${ }^{(35)}$. The variables included in the present analyses were age, sex, years of education (including schooling and post-schooling), parental birth country and parental income, current income level, pack years of smoking and both current and past physical activity levels. Indicators of cardiovascular health were measured by BMI, systolic blood pressure, diastolic blood pressure, and concentrations of LDL-cholesterol, HDL-cholesterol, total cholesterol and TAG. Medication use was also assessed for hypertension, high cholesterol levels and cardiac conditions. Descriptive statistics for these variables are presented in Table 1.

\section{Procedure}

All EPOCH participants were given the opportunity to participate in the lifetime diet assessment. The study was described to the participants individually during a study visit to CSIRO Animal Food and Health Sciences (the study centre). On providing written informed consent, they were
Table 1. Descriptive statistics for the subsample of the Older People, Omega-3 and Cognitive Health cohort who answered the Lifetime Diet Questionnaire

(Mean values and standard deviations)

\begin{tabular}{|c|c|c|}
\hline & Mean & SD \\
\hline Age (years) & $73 \cdot 12$ & 5.47 \\
\hline Years of education & $12 \cdot 91$ & $4 \cdot 16$ \\
\hline Smoking history (pack years*) & 9.83 & $17 \cdot 77$ \\
\hline $\mathrm{BMI}\left(\mathrm{kg} / \mathrm{m}^{2}\right)$ & $27 \cdot 27$ & 4.29 \\
\hline Systolic blood pressure $(\mathrm{mmHg})$ & $136 \cdot 83$ & $16 \cdot 48$ \\
\hline Diastolic blood pressure $(\mathrm{mmHg})$ & $76 \cdot 62$ & $9 \cdot 75$ \\
\hline HDL-cholesterol $(\mathrm{mmol} / \mathrm{l})$ & 1.39 & 0.36 \\
\hline LDL-cholesterol (mmol/l) & $3 \cdot 16$ & 0.86 \\
\hline Total cholesterol $(\mathrm{mmol} / \mathrm{l})$ & $5 \cdot 23$ & 1.00 \\
\hline TAG $(\mathrm{mmol} / \mathrm{l})$ & 1.48 & 0.64 \\
\hline Medication use & (\% of sample) & \\
\hline Cardiac medication & 26.4 & \\
\hline Cholesterol medication & $25 \cdot 9$ & \\
\hline Hypertensive medication & $42 \cdot 3$ & \\
\hline \multicolumn{3}{|l|}{$\operatorname{Sex}(\%)$} \\
\hline Female & $53 \cdot 7$ & \\
\hline $\begin{array}{l}\text { Current income ( }>\text { Australian } \\
\text { median for } 65 \text { years }+ \text { ) }(\%)\end{array}$ & 44.4 & \\
\hline \multicolumn{3}{|l|}{ Early-life sociodemographics (\%) } \\
\hline Parents with non-Anglo heritage & $13 \cdot 4$ & \\
\hline \multicolumn{3}{|l|}{ Parents' income } \\
\hline Low & $21 \cdot 0$ & \\
\hline Medium/high & 73.3 & \\
\hline Missing & $5 \cdot 7$ & \\
\hline
\end{tabular}

${ }^{*}$ Pack years $=($ cigarettes $/ \mathrm{d} \times$ years of smoking $) / 20$.

given the self-administered LDQ to complete at home and provided with detailed verbal and written instructions as to the study requirements. The questionnaire for each life period was completed in chronological order, $1 \mathrm{~d}$ at a time, over $5 \mathrm{~d}$ to minimise memories from one life period intruding into another period. In addition, given that each life period covered up to 15 years, the participants were asked to recall their most representative diet and to report their average consumption of seasonal foods. All participants completed the first four life periods: 'childhood'; 'early adulthood'; 'adulthood'; 'middle age'. The fifth life period, 'older age', only applied to the participants who were aged 80 years or over, of whom there were thirty.

\section{Statistical analyses}

Missing data. Participants who had responses missing for their whole life periods or $>80 \%$ of responses missing across any life period ( $n$ 3) were excluded from the following missing value analysis.

The remaining missing data in the LDQ were of two types: item non-response (mean per person 6.43 (SD 10.79)) and multiple consumption frequencies reported for a food item (mean per person 1.06 (SD 0.55)). Fatigue may cause elderly participants to skip questionnaire items for foods not eaten $^{(40,41)}$, so for this population, it was assumed that null responses generally equated to the 'rarely/never' consumption frequency. It has been shown that the greater the proportion of initially missing items, the greater the probability that these missing responses are likely to be true zeros (where zero equals 
non-consumption). This probability declines when the level of non-response reaches a threshold where 25 out of 80 items are missing responses (approximately 30\%) ${ }^{(40)}$. Thus, missing responses herein were equated with a food being 'rarely/ never' eaten (mean $n$ for all life periods 58 (SD 3.65)), except when a participant had less than the average number of non-responses (mean $n$ for all life periods 184.25 (SD $10 \cdot 84)$ ) or a large number ( $>30 \%$ ) of non-responses (mean $n$ for all life periods 30 (SD 5.88)) for items in each life period. These items, in addition to those with multiple responses, were missing at random and estimated with the missing value analysis in SPSS for Windows statistical package version 17.0.1 (SPSS, Inc.).

Dietary patterns. EFA was conducted on the food frequency response items for each separate life period assessed by the LDQ (EFA could not be conducted on the questionnaire data from the older-age period ( $>75$ years) because only thirty participants fell within this age range), using M-plus Statistical Analysis with Latent Variables version 5.1 (Muthén LK and Muthén BO). The weighted least-squares matrix estimator was used as estimates were based on polychoric correlations as opposed to the more commonly used Pearson's productmoment correlation coefficient. Polychoric correlations are appropriate when variables are ordinal or categorical, but can be assumed to represent a latent continuous construct, in this case, consumption frequency. Thus, the strength of linear relationships between ordinal variables that would be otherwise attenuated, due to the limited range of response frequencies, is better represented by a polychoric correlation coefficient rather than by Pearson's correlation. ${ }^{(42)}$.

The consumption frequency of all items was checked before analyses. It is feasible that relationships between foods that were either never or rarely consumed by the majority of participants may still define dietary patterns; however, any subsequent associations between such a factor and other measures would be driven by a very small proportion of the overall sample. Consequently, items that had $70 \%$ or greater 'rarely/never' responses were excluded from the EFA. The number of foods excluded and the number entered for each life period were as follows: childhood - seventeen foods excluded and fifty-seven foods entered; early adulthood - ten foods excluded and sixty-nine foods entered; adulthood seven foods excluded and seventy-one foods entered; middle age - four foods excluded and seventy-four foods entered.

A range of two to ten factors were extracted and an oblique rotation was specified (oblimin) to allow factors to be correlated. All factor correlations were below $0 \cdot 3$, so the orthogonal rotation varimax was subsequently chosen to promote a simple structure of the rotated solution and therefore aid in factor interpretability ${ }^{(43)}$.

An important decision when conducting a factor analysis is how many factors are to be retained. There is an extensive literature on the processes available to determine factor retention and their relative strengths and weaknesses, although theoretical plausibility is the overarching criterion $^{(44,45)}$. In these analyses, the factor retention decision was guided by the break point in the scree plot ${ }^{(46)}$, interpretability and having a clear factor structure ${ }^{(43)}$. The participants received a score on each factor extracted from the LDQ by weighting all food items by their factor loadings and then by summing the items ${ }^{(47)}$.

EFA was also conducted on the abbreviated (forty-seven items) CCFFQ in M-Plus, following a procedure similar to that followed for the LDQ and using the frequency of intake as the input variable. There were no missing data, and responses had a frequency range from 1 (rarely/never) to 10 (three or more times a day), so data were treated as continuous. Bread, milk, sugar and eggs were exceptions; these were assessed as units per $d$ (so the number of slices of bread, etc.) and recoded as binary values representing consumption $v$. non-consumption, except for eggs where the response frequency was number per week and the original coding was retained. M-plus can conduct EFA simultaneously on both binary and continuous variables; factors were extracted using the maximum-likelihood estimator.

Current diet and demographic variables as predictors of Lifetime Diet Questionnaire dietary patterns. Regression models were carried out using IBM SPSS for Windows statistical package version 20 (IBM Corporation) with each past dietary pattern being the outcome variable in separate models. First, current dietary patterns were used as predictors of each of the LDQ patterns across all life periods to determine the influence of current dietary intake on past diet recall; the average $R^{2}$ value for each life period indicated the average percentage of variance in recalled past diet that was accounted for by current diet. Next, demographic variables were entered to demonstrate relevant associations between these variables and past dietary intake as assessed by the LDQ.

The LDQ factor scores were normally distributed, and regression diagnostics showed no influential cases or serious violations of assumptions. Models were adjusted for current diet, physical activity (past and present) and the other past dietary factors; the study was powered at 0.8 to detect a medium effect size with $\alpha$ (two-tailed) at $0.05^{(48)}$.

In preliminary analyses, a number of LDQ factors showed higher-than-acceptable variance inflation factor values in the regression models, indicating multicollinearity among the LDQ factors. This would be problematic in further analyses when individual LDQ patterns were to be the predictors of model outcomes; when predictors are significantly related, their shared variance makes it impossible to reliably identify the individual contribution of any one of them ${ }^{(49)}$. One method to deal with multicollinearity among predictors is to compute principal components and use these components instead of the original variables in the analyses ${ }^{(50)}$; therefore, for each LDQ factor, a set of four unrelated principal components that accounted for approximately $80 \%$ of the shared variance among all the other past dietary patterns was created. Subsequently, these LDQ principal components, rather than the original LDQ factors, were entered as covariates in the models.

Lifetime Diet Questionnaire dietary patterns as predictors of cardiovascular risk factors. In separate analyses, cardiovascular risk factors were outcomes in the regression models with the individual LDQ factors as predictors. Multiple regression was used to test associations with the continuous variables of BMI, blood pressure and lipid measurements. 
The variables for BMI and TAG were $\log _{10}$-transformed, and those for systolic and diastolic blood pressure were square root-transformed to normalise the distributions ${ }^{(50)}$. Covariates were entered simultaneously into the models. These included age, sex, number of years of education, smoking history (pack years), income (parents' income for childhood and early adulthood and current income for adulthood and middle age), life period-specific physical activity, current physical activity, medication use, current dietary factors and the four principal components representing the other past dietary factors.

In total, three dichotomous variables (use/do not use medication) represented medication use for managing hypertension, cholesterol levels or cardiac conditions. Logistic regression was employed for models using these variables. Restrictions were imposed by sample size on the number of covariates possible to be included in the logistic regressions ${ }^{(51)}$ compared with the previous multiple regressions. These models were adjusted for age, sex, the relevant life-period physical activity variable, current physical activity and current diet; the number of 'events per variable' precluded the entry of the other LDQ principal component scores as covariates.

\section{Results}

A total of three factors were retained for each life period from the EFA of the LDQ. These factors and the food items with a loading of 0.3 and above are presented in Tables 2-5. No single factor was common to all periods, although there was considerable consistency in the factors across periods. These were the 'traditional Australian' and 'non-traditional Australian' patterns, a version of a 'processed fat and sweets' pattern, and a 'vegetable' or a 'fruit and vegetable' pattern. The 'traditional Australian' pattern was only evident in the two early-life periods of childhood and early adulthood; however, the 'non-traditional Australian' pattern was present in all periods except in childhood, and the 'processed fat and sweets' pattern was common across all periods except in early adulthood. The total percentage of variance accounted for by the factors in all the items of the LDQ for each life period was $35.7 \%$ in childhood, $31.87 \%$ in early adulthood, $26.93 \%$ in adulthood and $26 \cdot 12 \%$ in middle age.

Based on the same criteria, three factors similar to those extracted from the LDQ were extracted from the abbreviated CCFFQ using EFA. Loadings on each factor $>0.3$ and the variance accounted for in the items are presented in Table 6. Item loadings for the current dietary factors were generally lower than those for the LDQ with the highest loading value of 0.53 for processed meat on factor 2. Consequently, the extracted factors for current diet accounted for much less item variance than those for past diet.

Each of the past dietary patterns was significantly predicted by the three current dietary patterns, as shown by the highly

Table 2. Dietary patterns for childhood: item loading $>0.3$ and variance accounted for

\begin{tabular}{|c|c|c|c|c|c|}
\hline \multicolumn{2}{|c|}{$\begin{array}{l}\text { Factor } 1 \text { (variance } 9.65 \% \text { ): vegetable } \\
\text { and non-processed }\end{array}$} & \multicolumn{2}{|c|}{$\begin{array}{l}\text { Factor } 2 \text { (variance } 17 \cdot 70 \%): \\
\text { traditional Australian }\end{array}$} & \multicolumn{2}{|c|}{$\begin{array}{c}\left.\text { Factor } 3^{*} \text { (variance } 8.35 \%\right) \text { : } \\
\text { coffee and high-sugar, } \\
\text { high-fat extras }\end{array}$} \\
\hline Food items & Loadings & Food items & Loadings & Food items & Loadings \\
\hline Parsnip & 0.677 & White grapes & 0.908 & Sweet coffee & 0.943 \\
\hline Cruciferous vegetables & 0.630 & Red grapes & 0.847 & White coffee & 0.905 \\
\hline Rhubarb & 0.584 & Apricots/peaches & 0.793 & Snack food & 0.515 \\
\hline Beetroot & 0.550 & Citrus fruit & 0.733 & Soft drinks & 0.501 \\
\hline Carrots & 0.527 & Vegemite & 0.707 & Chocolate & 0.496 \\
\hline Plums & 0.473 & Melon & 0.704 & Nuts & 0.408 \\
\hline Lentils/beans & 0.458 & Pumpkin & 0.667 & Cherries & 0.403 \\
\hline Oats & 0.451 & Bananas & 0.649 & Chicken & 0.399 \\
\hline Pears & 0.450 & Butter & 0.615 & Ice cream & 0.390 \\
\hline Berries & 0.447 & Cream & 0.569 & Parsley & 0.317 \\
\hline Lettuce & 0.442 & Lettuce & 0.568 & Bananas & 0.308 \\
\hline Parsley & 0.440 & Figs & 0.566 & Fish (other) & 0.305 \\
\hline Green beans & 0.429 & High-fibre cereal & 0.515 & & \\
\hline Tomatoes & 0.403 & Nuts & 0.515 & & \\
\hline Cherries & 0.376 & Plums & 0.507 & & \\
\hline White rice & 0.375 & Red meat & 0.465 & & \\
\hline Vegetable soup & 0.361 & Ice cream & 0.455 & & \\
\hline Oily fish & 0.355 & Tomatoes & 0.442 & & \\
\hline Potatoes & 0.350 & Apples & 0.436 & & \\
\hline Onions & 0.323 & Spinach & 0.414 & & \\
\hline \multirow{8}{*}{ White tea } & 0.305 & Pears & 0.402 & & \\
\hline & & Eggs & 0.393 & & \\
\hline & & Beetroot & 0.390 & & \\
\hline & & Desserts & 0.386 & & \\
\hline & & Parsley & 0.340 & & \\
\hline & & Cheese & 0.331 & & \\
\hline & & Sweet tea & -0.365 & & \\
\hline & & White tea & -0.372 & & \\
\hline
\end{tabular}

* Item loadings on this factor were initially all negative, so the sign has been reversed on all loadings and in subsequent associations for ease of interpretation. 
Table 3. Dietary patterns for early adulthood: item loading $>0.3$ and variance accounted for

\begin{tabular}{|c|c|c|c|c|c|}
\hline \multicolumn{2}{|c|}{$\begin{array}{l}\text { Factor } 1 \text { (variance } 10.83 \% \text { ): } \\
\text { vegetable }\end{array}$} & \multicolumn{2}{|l|}{$\begin{array}{l}\text { Factor } 2 \text { (variance } 12 \cdot 24 \% \text { ): } \\
\text { traditional Australian }\end{array}$} & \multicolumn{2}{|c|}{$\begin{array}{l}\text { Factor } 3 \text { (variance } 8.80 \% \text { ): } \\
\text { non-traditional Australian }\end{array}$} \\
\hline Food items & Loadings & Food items & Loadings & Food items & Loadings \\
\hline Carrots & 0.721 & White grapes & 0.817 & Multi-grain bread & 0.677 \\
\hline Green beans & 0.663 & Red grapes & 0.750 & Whole-grain bread & 0.643 \\
\hline Tomatoes & 0.646 & Apricots/peaches & 0.653 & Red wine & 0.618 \\
\hline Beetroot & 0.609 & Ice cream & 0.610 & Herbs & 0.598 \\
\hline Lettuce & 0.582 & Soft drinks & 0.598 & Margarine (unspecified) & 0.597 \\
\hline Potatoes & 0.554 & Melon & 0.575 & Parsley & 0.505 \\
\hline Cruciferous vegetables & 0.546 & Citrus fruit & 0.518 & Other wine & 0.486 \\
\hline Parsnip & 0.543 & Nuts & 0.510 & Chicken & 0.381 \\
\hline Rhubarb & 0.509 & Snack food & 0.502 & Vegetable oil & 0.367 \\
\hline Pumpkin & 0.457 & Bananas & 0.489 & White rice & 0.352 \\
\hline Onions & 0.456 & Cherries & 0.479 & Black tea & 0.332 \\
\hline Spinach & 0.452 & Chocolate & 0.475 & Oily fish & 0.326 \\
\hline Parsley & 0.443 & Other wine & 0.449 & Melon & 0.314 \\
\hline Cows' milk & 0.397 & Vegemite & 0.436 & Sweet tea & -0.312 \\
\hline Plums & 0.394 & Sweet coffee & 0.431 & Desserts & -0.355 \\
\hline Citrus & 0.378 & Red wine & 0.421 & Butter & -0.617 \\
\hline Apples & 0.369 & Pears & 0.404 & White bread & -0.749 \\
\hline Cheese & 0.354 & Berries & 0.403 & & \\
\hline Vegetable soup & 0.349 & White coffee & 0.394 & & \\
\hline Oats & 0.332 & Take-away food & 0.377 & & \\
\hline Herbs & 0.319 & Pumpkin & 0.368 & & \\
\hline \multirow[t]{10}{*}{ Pears } & 0.303 & Chicken & 0.363 & & \\
\hline & & Lettuce & 0.361 & & \\
\hline & & Parsley & 0.359 & & \\
\hline & & Vegetable oil & 0.358 & & \\
\hline & & High-fibre cereal & 0.346 & & \\
\hline & & Cream & 0.331 & & \\
\hline & & Plums & 0.330 & & \\
\hline & & Apples & 0.327 & & \\
\hline & & Fish (other than oily fish or shellfish) & 0.318 & & \\
\hline & & Desserts & 0.318 & & \\
\hline
\end{tabular}

significant $F$ values in Table 7. However, the percentage of variance accounted for by current diet in the past dietary factors from each life period increased incrementally over the life course. In childhood, current diet contributed $7 \cdot 6 \%$ of the variance in dietary patterns for this period, while by middle age current diet contributed $41.5 \%$ of the variance in the later patterns.

Demographic and cardiovascular health variables were significantly associated with lifetime dietary patterns after controlling for current dietary intake in this sample of older Australians. The standardised $\beta$ weights for the relationships between the LDQ patterns and the demographic variables are presented in Table 8.

Age was the most robust predictor of the dietary patterns with one association being found in every life period and two in early adulthood and adulthood. Age positively predicted the 'vegetable' or 'fruit and vegetable' pattern in childhood, early adulthood and adulthood. It also negatively predicted the 'non-traditional Australian' pattern (early adulthood and middle age) and the 'processed, high-sugar and high-fat' pattern in adulthood. Being female predicted higher scores on the 'vegetable' pattern in early adulthood, and men scored higher on the 'processed, high-sugar and highfat' pattern in mid-life. In adulthood, a greater number of years spent in formal education was associated with higher scores on the 'non-traditional Australian' pattern. Having one or both parents from a non-Anglo background strongly predicted a higher score on the 'non-traditional Australian' dietary pattern in early adulthood, which also positively predicted income. Childhood was the only life period where physical activity was associated with a dietary pattern; it positively predicted the 'vegetable and non-processed' pattern.

The results did not change substantially when current dietary factors or the LDQ principal components were excluded from the models; the exception was for associations between the LDQ patterns and smoking history. In the primary models, when the variance from other past periods was controlled for, smoking did not predict any dietary pattern. When the LDQ components were excluded, however, smoking history negatively predicted the healthful 'non-traditional Australian' patterns, in addition to those with high loadings of vegetables, fruit and those that were non-processed.

One lifetime dietary pattern from childhood and two from adulthood significantly predicted markers of current cardiovascular health in the sample. Table 9 presents multiple regression models for the continuous outcomes, and Table 10 presents logistic regression models for the dichotomous outcomes.

Higher scores on the childhood 'traditional Australian' pattern predicted higher HDL-cholesterol levels and a 3.6\% reduced chance of using cholesterol medication. In adulthood, the 'processed, high-sugar and high-fat' pattern negatively predicted HDL-cholesterol levels, and the 'non-traditional 
Table 4. Dietary patterns for adulthood: item loading $>0.3$ and variance accounted for

\begin{tabular}{|c|c|c|c|c|c|}
\hline \multicolumn{2}{|c|}{$\begin{array}{l}\text { Factor } 1 \text { (variance } 10.26 \% \text { ): } \\
\text { fruit and vegetable }\end{array}$} & \multicolumn{2}{|c|}{$\begin{array}{l}\text { Factor } 2 \text { (variance } 10.31 \% \text { ): } \\
\text { non-traditional Australian }\end{array}$} & \multicolumn{2}{|c|}{$\begin{array}{c}\text { Factor } 3 \text { (variance } 6.36 \% \text { ): } \\
\text { processed, high-sugar and high-fat }\end{array}$} \\
\hline Food items & Loadings & Food items & Loadings & Food items & Loadings \\
\hline Carrots & 0.578 & Herbs & 0.673 & Soft drinks & 0.654 \\
\hline Apples & 0.575 & Peppers & 0.635 & Take-away food & 0.581 \\
\hline Plums & 0.553 & Red wine & 0.595 & Ice cream & 0.569 \\
\hline Beetroot & 0.539 & Parsley & 0.579 & White bread & 0.566 \\
\hline Apricots/peaches & 0.529 & Olive oil & 0.537 & Sweet coffee & 0.549 \\
\hline Citrus fruit & 0.516 & Yogurt & 0.522 & Sweet tea & 0.539 \\
\hline Tomatoes & 0.510 & Seafood & 0.508 & Snack food & 0.469 \\
\hline Green beans & 0.508 & Other wine & 0.508 & Chocolate & 0.451 \\
\hline Bananas & 0.499 & Red grapes & 0.502 & Sausages & 0.428 \\
\hline White grapes & 0.486 & Chicken & 0.470 & Desserts & 0.377 \\
\hline Parsley & 0.478 & Multi-grain bread & 0.459 & Cows' milk & 0.352 \\
\hline Lettuce & 0.477 & Whole-grain bread & 0.442 & White coffee & 0.342 \\
\hline Red grapes & 0.457 & Brown rice & 0.442 & Cream & 0.310 \\
\hline Pears & 0.453 & Nuts & 0.427 & Whole-grain bread & -0.395 \\
\hline Rhubarb & 0.450 & Melon & 0.417 & & \\
\hline Cruciferous vegetables & 0.417 & White grapes & 0.392 & & \\
\hline Pumpkin & 0.404 & White rice & 0.385 & & \\
\hline Cheese & 0.394 & Cherries & 0.366 & & \\
\hline Parsnip & 0.386 & Lentils/beans & 0.366 & & \\
\hline Herbs & 0.384 & Margarine (unspecified) & 0.358 & & \\
\hline Cherries & 0.374 & Vegetable oil & 0.348 & & \\
\hline Spinach & 0.371 & Berries & 0.327 & & \\
\hline Vegetable soup & 0.363 & Fish (other) & 0.327 & & \\
\hline Potatoes & 0.346 & Take-away food & 0.313 & & \\
\hline Oats & 0.344 & Butter & -0.329 & & \\
\hline Berries & 0.324 & Red meat & -0.342 & & \\
\hline Onions & 0.320 & White bread & -0.428 & & \\
\hline Melon & 0.319 & Potatoes & -0.512 & & \\
\hline High-fibre cereal & 0.316 & & & & \\
\hline Vegemite & 0.313 & & & & \\
\hline Brown rice & 0.305 & & & & \\
\hline
\end{tabular}

Australian' pattern predicted a $6 \cdot 2 \%$ reduced chance of using cardiac medication in later life.

For the medication outcomes, associations were not adjusted for possible shared variance with the other lifetime dietary patterns due to the limited number of covariates able to be included to ensure adequate power, but in each case, no more than one pattern was a significant predictor. Therefore, it was reasonable to assume that controlling for the other dietary patterns would not change the results.

\section{Discussion}

Lifetime dietary intake is a potentially modifiable environmental contributor of health and well-being in older age. The LDQ provides a possible means of assessing this intake in older cognitively healthy people, with dietary patterns extracted for each life period of the questionnaire proving to be useful for representing this intake.

Patterns similar to those extracted from the LDQ have been found in other studies across a variety of populations. A version of the 'sweets or desserts' pattern has been found to be the most reproducible ${ }^{(7)}$ and was present for all life periods of the LDQ, except for early adulthood. The 'non-traditional Australian' pattern that emerged in three of the four periods of the LDQ comprised many foods that have been associated in other studies with a 'prudent' style or healthful diet such as whole grains, herbs, chicken and fish, fruit, olives and olive oil, red wine and grapes ${ }^{(5,7)}$; it was named 'non-traditional' in the present study to differentiate it from the 'traditional Australian' pattern. The 'traditional Australian' pattern also had high loadings from particular vegetables and fruit (such as lettuce, pumpkin, beetroot, grapes and pears) but, in combination with other items such as ice cream, vegemite (a yeast extract spread), butter, cream and red meat, this pattern represented dietary intake that was more specific to an Australian population with a predominantly Anglo-Saxon heritage, particularly in the period when participants were children or young adults ${ }^{(52)}$. The 'fruit and vegetable' pattern found in both adulthood and middle age is also common across multiple populations when a dietary pattern analysis is applied to a FFQ. Patterns dominated by fruit and vegetable intake are often also known as 'health aware' or 'healthful' to differentiate them from patterns high in processed foods or sweets $^{(7)}$.

It is well established that dietary intake changes over time $e^{(53-55)}$ and that these changes are determined by changes in individuals' social and demographic circumstances ${ }^{(53,56)}$. The LDQ has been previously demonstrated to capture changes in dietary intake over the lifespan ${ }^{(32)}$, thereby giving some validity to the long-term dietary recall process. These findings have been strengthened by the results of the present study. When current diet was used to predict each 
Table 5. Dietary patterns for middle age: item loading $>0.3$ and variance accounted for

\begin{tabular}{|c|c|c|c|c|c|}
\hline \multicolumn{2}{|c|}{$\begin{array}{l}\text { Factor } 1 \text { (variance } 12.33 \% \text { ): fruit, } \\
\text { vegetable and non-processed }\end{array}$} & \multicolumn{2}{|c|}{$\begin{array}{l}\text { Factor } 2 \text { (variance } 7.33 \% \text { ): } \\
\text { non-traditional Australian }\end{array}$} & \multicolumn{2}{|c|}{$\begin{array}{c}\text { Factor } 3 \text { (variance } 6.46 \% \text { ): } \\
\text { processed, high-sugar and high-fat }\end{array}$} \\
\hline Food items & Loadings & Food items & Loadings & Food items & Loadings \\
\hline Apricots/peaches & 0.724 & Herbs & 0.697 & Soft drinks & 0.635 \\
\hline Plums & 0.670 & Olives & 0.662 & Ice cream & 0.589 \\
\hline Cherries & 0.625 & Parsley & 0.563 & Desserts & 0.583 \\
\hline Pears & 0.597 & Seafood & 0.529 & Snack food & 0.529 \\
\hline Apples & 0.583 & Olive oil & 0.520 & Sausages & 0.520 \\
\hline Citrus fruit & 0.574 & Red wine & 0.491 & White bread & 0.504 \\
\hline Lettuce & 0.537 & Peppers & 0.443 & Cream & 0.485 \\
\hline White grapes & 0.533 & Onions & 0.440 & Take-away food & 0.456 \\
\hline Bananas & 0.516 & Other wine & 0.435 & Chocolate & 0.456 \\
\hline Berries & 0.511 & Red grapes & 0.425 & Red meat & 0.402 \\
\hline Tomatoes & 0.505 & Mangoes & 0.409 & Sweet tea & 0.397 \\
\hline Parsley & 0.504 & Nuts & 0.394 & Sweet coffee & 0.390 \\
\hline Rhubarb & 0.503 & Fish (other) & 0.364 & Cows' milk & 0.332 \\
\hline Cruciferous vegetables & 0.487 & Melon & 0.339 & Vegemite & 0.328 \\
\hline Beetroot & 0.485 & White grapes & 0.330 & Green beans & 0.313 \\
\hline Red grapes & 0.483 & Potatoes & -0.406 & & \\
\hline Carrots & 0.481 & & & & \\
\hline Brown rice & 0.456 & & & & \\
\hline Parsnip & 0.440 & & & & \\
\hline Peppers & 0.420 & & & & \\
\hline Melon & 0.419 & & & & \\
\hline Green beans & 0.418 & & & & \\
\hline Whole-grain bread & 0.413 & & & & \\
\hline Spinach & 0.412 & & & & \\
\hline Yogurt & 0.402 & & & & \\
\hline Herbs & 0.398 & & & & \\
\hline Oats & 0.381 & & & & \\
\hline Lentils/beans & 0.365 & & & & \\
\hline Vegetable soup & 0.351 & & & & \\
\hline Oily fish & 0.345 & & & & \\
\hline Mangoes & 0.315 & & & & \\
\hline Onions & 0.314 & & & & \\
\hline Pumpkin & 0.303 & & & & \\
\hline
\end{tabular}

of the past dietary patterns, the percentage of variance accounted for by current diet incrementally increased from childhood, where current diet only accounted for $7 \cdot 6 \%$ of variance, to middle age, where current diet accounted for $41.5 \%$ of the variance in recalled intake for this later-life period.

Age, sex and markers of socio-economic status are robust predictors of dietary intake across a wide spectrum of populations ${ }^{(6,57)}$. These variables also predicted patterns from the LDQ after controlling for the influence of both current diet and other past dietary patterns; however, interpretation of these associations in the context of previous findings is challenging, given that no studies have followed the eating patterns of individuals over their whole lifetime. Dietary choices across life are determined by direct cohort effects, for example, the imposed frugality during the Second World War, and within-person effects, such as having a greater disposable income at various life stages, or particular health concerns that necessitate dietary modifications ${ }^{(58)}$. In this cohort, it was evident that participants' diet, as captured by the dietary patterns of the LDQ, particularly reflected the influence of the cultural and social determinants of dietary intake across the various life periods.

Catalysts for change in Australian eating habits were the post-war influx of European migrants and the introduction of many previously unavailable foods and meal choices ${ }^{(52)}$. Accordingly, in this sample, having non-Anglo parents strongly predicted a non-traditional Australian diet in early adulthood. In this period also, being of older age negatively predicted this 'non-traditional Australian' pattern. Early adulthood for the older participants would have spanned the late 1940s to the beginning of the 1960s, and it is possible that the impact of European immigration was yet to be assimilated into mainstream dietary practices, which may explain the negative association.

Changes in food availability in Australia were also reflected by the older members' early-life dietary patterns. Higher consumption of the 'vegetable and non-processed' pattern in childhood and a 'vegetable' pattern in early adulthood was predicted by older age; these were frugal eating patterns defined by high loadings from garden-grown vegetables and represent a diet common to the war and pre-war years in Australia ${ }^{(52)}$. For these older participants, the higher consumption of dietary patterns high in vegetables continued into adulthood also, with older age positively predicting the adult 'fruit and vegetable' pattern, and in middle age, this more conservative diet was reflected by the negative association between age and the "non-traditional Australian' dietary pattern. 
Table 6. Current dietary factors extracted from the Cancer Council FFQ (CCFFQ): loadings $>0.3$ and variance accounted for

\begin{tabular}{|c|c|c|c|c|c|}
\hline \multicolumn{2}{|c|}{ Factor 1 (variance $9.37 \%$ ): health aware } & \multicolumn{2}{|c|}{$\begin{array}{c}\text { Factor } 2 \text { (variance } 4.53 \%): \\
\text { processed }\end{array}$} & \multicolumn{2}{|c|}{$\begin{array}{c}\text { Factor } 3 \text { (variance } 3.11 \% \text { ): } \\
\text { traditional vegetables }\end{array}$} \\
\hline Food items & Loadings & Food items & Loadings & Food items & Loadings \\
\hline \multicolumn{6}{|l|}{ Current diet* ${ }^{*}$} \\
\hline Peppers & 0.568 & Processed meat & 0.530 & Carrots & 0.490 \\
\hline Beans (chick, peas/lentils, etc.) & 0.560 & Ice cream & 0.445 & Cruciferous vegetables & 0.456 \\
\hline Mangoes & 0.487 & Take-away food & 0.444 & Pumpkin & 0.356 \\
\hline Apples & 0.466 & Bread & 0.432 & Beans/peas & 0.341 \\
\hline Spinach & 0.461 & Sweets & 0.406 & Spirits & -0.390 \\
\hline Onions/garlic & 0.460 & Snack food & 0.401 & & \\
\hline Green salad & 0.454 & Red meat & 0.350 & & \\
\hline Yogurt & 0.446 & & & & \\
\hline Pears & 0.438 & & & & \\
\hline Strawberries & 0.436 & & & & \\
\hline Melon & 0.434 & & & & \\
\hline Stone fruit & 0.428 & & & & \\
\hline Nuts & 0.390 & & & & \\
\hline Bananas & 0.368 & & & & \\
\hline Cruciferous veqetables & 0.364 & & & & \\
\hline Carrots & 0.363 & & & & \\
\hline Tomatoes & 0.327 & & & & \\
\hline Fish (tinned) & 0.324 & & & & \\
\hline Citrus fruit & 0.320 & & & & \\
\hline
\end{tabular}

* Only intake frequency of foods common to the Lifetime Diet Questionnaire and CCFFQ was assessed.

Sex predicted dietary patterns in early adulthood and middle age. Differences in dietary patterns consumed by men and women are a robust finding in the dietary pattern literature and, in general, women have been found to follow healthier dietary patterns than men ${ }^{(28,59)}$. This finding was replicated to some extent for the patterns from the LDQ; the exception was the higher consumption of the healthful 'nontraditional Australian' pattern by males in early adulthood. This borderline association was unexpected, and it is possible that there were other unassessed sociodemographic variables confounding the relationship.

The relationship between higher educational attainment and healthy dietary choices has been well established ${ }^{(60-62)}$. It is unknown, however, whether this association is also historically relevant, although others did find that higher education positively predicted increased consumption of an 'ethnic foods and alcohol' pattern during adulthood in the decade from 1989 to $1999^{(55)}$. The adulthood 'non-traditional Australian' dietary pattern (which could be considered 'ethnic' during the relevant time period) had high loadings from herbs, peppers, all wine, olive oil, yogurt, seafood, whole grains, chicken and nuts, with negative loadings from butter, meat, bread and potatoes. This pattern was strongly and positively predicted by years of formal schooling. Formal education (including individuals' highest level of post-school qualification) would have been completed for the majority of people by adulthood; it is appropriate then that the association between higher education and a healthful diet emerged in this life period.

Interestingly, the relationship did not carry through into mid-life. Given the relatively high amount of shared variance that was demonstrated between current dietary intake and

Table 7. Contribution of current diet to the variance in past dietary factors

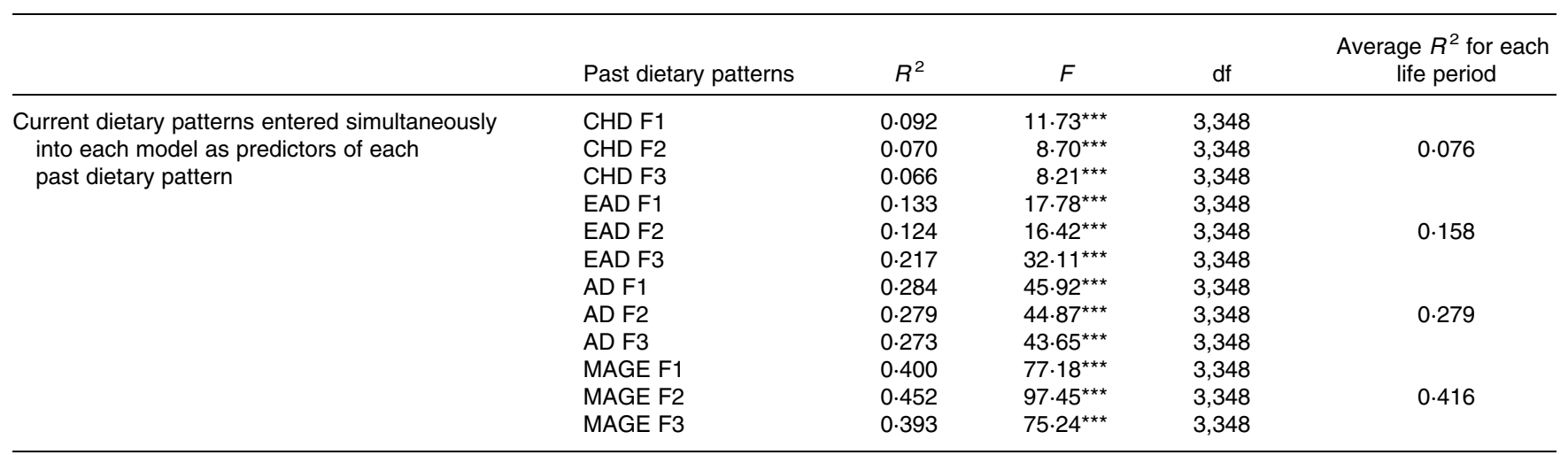

CHD, childhood; $E A D$, early adulthood; $A D$, adulthood; MAGE, middle age. ${ }^{* \star *} P<0.001$. 
Table 8. Demographic predictors of lifetime dietary patterns*

\begin{tabular}{|c|c|c|c|c|c|c|c|c|c|c|c|c|c|c|}
\hline \multirow[b]{2}{*}{$\begin{array}{l}\text { Dietary } \\
\text { patterns }\end{array}$} & \multicolumn{2}{|l|}{ Age } & \multicolumn{2}{|l|}{ Sex } & \multicolumn{2}{|c|}{ Education } & \multicolumn{2}{|c|}{ Anglo parents } & \multicolumn{2}{|c|}{ Income† } & \multicolumn{2}{|c|}{ Pack years } & \multicolumn{2}{|c|}{$\begin{array}{c}\text { Life-period physical } \\
\text { activity }\end{array}$} \\
\hline & $\begin{array}{l}\text { Standardised } \\
\beta \text { weights }\end{array}$ & $P$ & $\begin{array}{l}\text { Standardised } \\
\beta \text { weights }\end{array}$ & $P$ & $\begin{array}{l}\text { Standardised } \\
\beta \text { weights }\end{array}$ & $P$ & $\begin{array}{l}\text { Standardised } \\
\beta \text { weights }\end{array}$ & $P$ & $\begin{array}{l}\text { Standardised } \\
\beta \text { weights }\end{array}$ & $P$ & $\begin{array}{l}\text { Standardised } \\
\beta \text { weights }\end{array}$ & $P$ & $\begin{array}{l}\text { Standardised } \\
\beta \text { weights }\end{array}$ & $P$ \\
\hline $\begin{array}{l}\mathrm{CHD} \text { vegetable and } \\
\text { non-processed }\end{array}$ & 0.092 & 0.047 & 0.028 & 0.546 & -0.055 & 0.213 & 0.004 & 0.934 & -0.012 & 0.784 & 0.018 & 0.682 & 0.146 & 0.001 \\
\hline $\begin{array}{l}\text { CHD traditional } \\
\text { Australian }\end{array}$ & 0.000 & 0.987 & 0.022 & 0.639 & 0.026 & 0.556 & 0.039 & 0.371 & -0.005 & 0.910 & -0.016 & 0.718 & -0.055 & $0 \cdot 195$ \\
\hline $\begin{array}{l}\text { CHD coffee and } \\
\text { high-sugar, } \\
\text { high-fat extras }\end{array}$ & 0.093 & 0.060 & 0.058 & 0.250 & -0.037 & 0.440 & 0.090 & 0.058 & 0.015 & 0.750 & -0.001 & 0.991 & -0.027 & 0.570 \\
\hline EAD vegetable & 0.097 & 0.024 & 0.118 & 0.007 & -0.055 & 0.187 & 0.061 & 0.145 & 0.051 & 0.208 & -0.032 & 0.443 & 0.078 & 0.052 \\
\hline $\begin{array}{l}\text { EAD traditional } \\
\text { Australian }\end{array}$ & -0.064 & 0.083 & -0.066 & 0.080 & -0.023 & 0.513 & -0.050 & 0.157 & 0.012 & 0.725 & -0.006 & 0.857 & -0.066 & 0.056 \\
\hline $\begin{array}{l}\text { EAD non-traditional } \\
\text { Australian }\end{array}$ & -0.113 & 0.013 & -0.091 & 0.050 & -0.079 & 0.071 & -0.118 & 0.007 & 0.083 & 0.048 & -0.025 & 0.573 & -0.045 & 0.281 \\
\hline $\begin{array}{l}\text { AD fruit and } \\
\text { vegetable }\end{array}$ & 0.081 & 0.011 & 0.048 & 0.143 & 0.037 & 0.224 & 0.039 & 0.197 & -0.010 & 0.746 & -0.016 & 0.606 & 0.008 & 0.782 \\
\hline $\begin{array}{l}\text { AD non-traditional } \\
\text { Australian }\end{array}$ & -0.008 & 0.795 & -0.034 & 0.291 & 0.084 & 0.005 & -0.007 & 0.828 & 0.046 & $0 \cdot 130$ & -0.043 & $0 \cdot 160$ & -0.016 & 0.585 \\
\hline $\begin{array}{l}\text { AD processed, } \\
\text { high-sugar and } \\
\text { high-fat }\end{array}$ & -0.169 & $<0.001$ & -0.027 & 0.536 & -0.051 & 0.195 & 0.021 & 0.596 & -0.003 & 0.935 & 0.008 & 0.849 & 0.052 & 0.184 \\
\hline $\begin{array}{l}\text { MAGE fruit, } \\
\text { vegetable and } \\
\text { non-processed }\end{array}$ & 0.015 & 0.652 & 0.062 & 0.069 & 0.000 & 0.988 & 0.006 & 0.838 & 0.007 & 0.833 & -0.018 & 0.577 & 0.010 & 0.746 \\
\hline $\begin{array}{l}\text { MAGE non-traditional } \\
\text { Australian }\end{array}$ & -0.082 & 0.012 & -0.026 & 0.443 & -0.021 & 0.495 & 0.008 & 0.793 & 0.006 & 0.849 & 0.036 & 0.255 & -0.018 & 0.572 \\
\hline $\begin{array}{l}\text { MAGE processed, } \\
\text { high-sugar and } \\
\text { high-fat }\end{array}$ & 0.076 & 0.053 & $-0 \cdot 100$ & 0.013 & -0.016 & 0.660 & -0.026 & 0.477 & -0.014 & 0.712 & -0.003 & 0.930 & -0.061 & $0 \cdot 105$ \\
\hline
\end{tabular}

CHD, childhood; EAD, early adulthood; AD, adulthood; MAGE, middle age.

* Models additionally adjusted for current dietary intake, current physical activity and other Lifetime Diet Questionnaire dietary patterns.

†Parents' income level (low $v$. medium/high) for the life periods of childhood and early adulthood; current income as proxy for income in adulthood and middle age. 
Table 9. Lifetime dietary patterns as predictors of cardiovascular outcomes*

\begin{tabular}{|c|c|c|c|c|c|c|c|c|c|c|c|c|c|c|}
\hline \multirow[b]{2}{*}{ Dietary patterns } & \multicolumn{2}{|c|}{ BMI $\left(\mathrm{kg} / \mathrm{m}^{2}\right)$} & \multicolumn{2}{|c|}{ Systolic BP (mmHg) } & \multicolumn{2}{|c|}{ Diastolic BP (mmHg) } & \multicolumn{2}{|c|}{$\begin{array}{l}\text { HDL-cholesterol } \\
\quad(\mathrm{mmol} / \mathrm{l})\end{array}$} & \multicolumn{2}{|c|}{$\begin{array}{l}\text { LDL-cholesterol } \\
\quad(\mathrm{mmol} / \mathrm{l})\end{array}$} & \multicolumn{2}{|c|}{$\begin{array}{l}\text { Total cholesterol } \\
\qquad(\mathrm{mmol} / \mathrm{l})\end{array}$} & \multicolumn{2}{|c|}{ TAG $(\mathrm{mmol} / \mathrm{l})$} \\
\hline & $\begin{array}{l}\text { Standardised } \\
\beta \text { weights }\end{array}$ & $P$ & $\begin{array}{l}\text { Standardised } \\
\beta \text { weights }\end{array}$ & $P$ & $\begin{array}{l}\text { Standardised } \\
\beta \text { weights }\end{array}$ & $P$ & $\begin{array}{l}\text { Standardised } \\
\beta \text { weights }\end{array}$ & $P$ & $\begin{array}{l}\text { Standardised } \\
\beta \text { weights }\end{array}$ & $P$ & $\begin{array}{l}\text { Standardised } \\
\beta \text { weights }\end{array}$ & $P$ & $\begin{array}{l}\text { Standardised } \\
\beta \text { weights }\end{array}$ & $P$ \\
\hline $\begin{array}{l}\mathrm{CHD} \text { vegetable } \\
\text { and non- } \\
\text { processed }\end{array}$ & 0.040 & 0.589 & -0.064 & 0.391 & -0.050 & 0.497 & 0.000 & 0.998 & -0.015 & 0.819 & -0.034 & 0.608 & -0.060 & 0.422 \\
\hline $\begin{array}{l}\text { CHD traditional } \\
\text { Australian }\end{array}$ & -0.101 & $0 \cdot 176$ & -0.149 & 0.050 & -0.062 & 0.416 & 0.143 & 0.049 & 0.096 & $0 \cdot 148$ & 0.108 & 0.114 & -0.057 & 0.453 \\
\hline $\begin{array}{l}\text { CHD coffee and } \\
\text { high-sugar, } \\
\text { high-fat } \\
\text { extras }\end{array}$ & -0.066 & 0.327 & 0.029 & 0.672 & 0.011 & 0.874 & 0.045 & 0.498 & -0.006 & 0.916 & -0.007 & 0.904 & -0.065 & 0.344 \\
\hline EAD vegetable & 0.115 & 0.136 & 0.109 & 0.159 & 0.151 & 0.052 & -0.093 & 0.214 & -0.064 & 0.348 & -0.086 & 0.224 & 0.084 & 0.287 \\
\hline $\begin{array}{l}\text { EAD traditional } \\
\text { Australian }\end{array}$ & 0.053 & 0.560 & 0.018 & 0.840 & 0.113 & 0.217 & 0.033 & 0.703 & -0.045 & 0.577 & 0.002 & 0.983 & 0.005 & 0.957 \\
\hline $\begin{array}{l}\text { EAD non- } \\
\text { traditional } \\
\text { Australian }\end{array}$ & 0.140 & 0.053 & -0.032 & 0.667 & $0 \cdot 130$ & 0.076 & -0.023 & 0.742 & -0.008 & 0.900 & 0.015 & 0.824 & 0.074 & 0.318 \\
\hline $\begin{array}{l}A D \text { fruit and } \\
\text { vegetable }\end{array}$ & 0.003 & 0.973 & -0.040 & 0.692 & -0.138 & 0.168 & -0.146 & $0 \cdot 127$ & -0.030 & 0.737 & -0.050 & 0.580 & 0.065 & 0.533 \\
\hline $\begin{array}{l}\text { AD non- } \\
\text { traditional } \\
\text { Australian }\end{array}$ & 0.010 & 0.918 & 0.095 & 0.350 & 0.006 & 0.950 & -0.172 & 0.075 & 0.061 & 0.499 & 0.010 & 0.918 & 0.065 & 0.535 \\
\hline $\begin{array}{l}\text { AD processed, } \\
\text { high-sugar } \\
\text { and high-fat }\end{array}$ & 0.020 & 0.788 & -0.013 & 0.867 & -0.121 & 0.113 & -0.178 & 0.015 & 0.016 & 0.811 & -0.038 & 0.586 & 0.062 & 0.439 \\
\hline $\begin{array}{l}\text { MAGE fruit, } \\
\text { vegetable } \\
\text { and non- } \\
\text { processed }\end{array}$ & -0.031 & 0.749 & $0 \cdot 137$ & $0 \cdot 160$ & 0.013 & 0.896 & 0.069 & 0.460 & 0.026 & 0.766 & 0.033 & 0.714 & -0.038 & 0.713 \\
\hline $\begin{array}{l}\text { MAGE non- } \\
\text { traditional } \\
\text { Australian }\end{array}$ & -0.067 & 0.483 & -0.077 & 0.430 & -0.189 & 0.053 & 0.087 & 0.352 & 0.015 & 0.863 & 0.013 & 0.886 & -0.033 & 0.746 \\
\hline $\begin{array}{l}\text { MAGE } \\
\text { processed, } \\
\text { high-sugar } \\
\text { and high-fat }\end{array}$ & 0.055 & 0.497 & 0.057 & 0.485 & 0.130 & 0.114 & -0.044 & 0.577 & -0.023 & 0.756 & -0.026 & 0.726 & 0.047 & 0.585 \\
\hline
\end{tabular}

BP, blood pressure; $C H D$, childhood; EAD, early adulthood; $A D$, adulthood; MAGE, middle age.

*Models adjusted for age, sex, education, smoking history, income, life-period physical activity, current dietary intake, other past dietary factors and medication use. BMI, log ${ }_{10}$-transformed; systolic BP and diastolic BP, square root-transformed; TAG, $\log _{10}$-transformed. 
Table 10. Lifetime dietary patterns as predictors of cardiovascular medication use* (Odds ratios and $95 \%$ confidence intervals)

\begin{tabular}{|c|c|c|c|c|c|c|}
\hline \multirow[b]{2}{*}{ Dietary patterns } & \multicolumn{2}{|c|}{ Cardiac medication $†$} & \multicolumn{2}{|c|}{$\begin{array}{l}\text { Cholesterol } \\
\text { medicationt }\end{array}$} & \multicolumn{2}{|c|}{$\begin{array}{c}\text { Hypertensive } \\
\text { medication† }\end{array}$} \\
\hline & OR & $95 \% \mathrm{Cl}$ & OR & $95 \% \mathrm{Cl}$ & OR & $95 \% \mathrm{Cl}$ \\
\hline $\mathrm{CHD}$ vegetable and non-processed & 1.022 & $0.958,1.090$ & 0.996 & $0.934,1.061$ & 0.958 & $0.903,1.017$ \\
\hline CHD traditional Australian & 0.994 & $0.960,1.029$ & 0.964 & $0.931,0.998$ & 0.978 & $0.949,1.009$ \\
\hline CHD coffee and high-sugar, high-fat extras & 1.070 & $0.993,1.153$ & 0.983 & $0.916,1.054$ & 1.038 & $0.972,1.107$ \\
\hline EAD vegetable & 1.005 & $0.951,1.062$ & 1.022 & $0.968,1.079$ & 0.980 & $0.934,1.029$ \\
\hline EAD traditional Australian & 0.973 & $0.930,1.019$ & 0.989 & $0.945,1.034$ & 1.003 & $0.963,1.044$ \\
\hline EAD non-traditional Australian & 0.960 & $0.901,1.024$ & 0.997 & $0.938,1.059$ & 1.002 & $0.949,1.059$ \\
\hline AD fruit and vegetable & 0.970 & $0.913,1.030$ & 1.031 & $0.973,1.093$ & 1.014 & $0.963,1.069$ \\
\hline AD non-traditional Australian & 0.938 & $0.886,0.993$ & 0.995 & $0.943,1.049$ & 1.011 & $0.963,1.062$ \\
\hline AD processed, high-sugar and high-fat & 1.019 & $0.940,1.104$ & 1.024 & $0.947,1.107$ & 1.001 & $0.933,1.075$ \\
\hline MAGE fruit, vegetable and non-processed & 0.989 & $0.941,1.039$ & 1.038 & $0.988,1.091$ & 0.978 & $0.936,1.023$ \\
\hline MAGE non-traditional Australian & 0.965 & $0.896,1.039$ & 1.020 & $0.948,1.096$ & 1.026 & $0.960,1.096$ \\
\hline MAGE processed, high-sugar and high-fat & 0.995 & $0.915,1.081$ & 0.975 & $0.898,1.058$ & 0.986 & $0.915,1.062$ \\
\hline
\end{tabular}

CHD, childhood; EAD, early adulthood; $A D$, adulthood; MAGE, middle age.

* Logistic regression models adjusted for age, sex, current dietary intake, current physical activity and life-period physical activity. $\dagger$ Medication use coded as 1 .

diet in middle age, it is theoretically possible that controlling for current diet in the models suppressed the association; however, supplementary analyses that excluded the current and other past dietary factors failed to reveal any association between years of education and healthy dietary choices in middle age. It appears that for this life period, there were other more influential factors that determined dietary intake.

Childhood was the only period in which physical activity specific to the life period was associated with a dietary pattern from the LDQ with higher levels of activity predicting the 'non-processed vegetable' pattern. This is consistent with other findings of a positive relationship between healthier patterns of intake and higher levels of physical activity ${ }^{(15,28)}$. In recent years, the synergistic interaction between dietary choice and physical activity has been a widely promoted public health message ${ }^{(63)}$, with the aim of reducing the risk and incidence of disease in society. During the earlier years of the six decades covered by the LDQ, however, physical activity and dietary choices may not have always been so closely related, which could explain the overall lack of associations between dietary patterns from the LDQ and historical levels of physical activity. Alternatively, the lack of associations between the lifetime dietary patterns and lifetime physical activity could be explained by some systematic error in long-term recall on both measures.

In the fully adjusted models, smoking history was not associated with any of the dietary patterns during any life period. This could be considered unexpected, given that the relationship between smoking and dietary choices is a robust one in the literature ${ }^{(64-66)}$; however, when the influence of the other lifetime patterns was not controlled for, smoking history significantly predicted the dietary patterns. This finding suggests that lifetime smoking habits, in particular, are not related to variance specific to a particular life-period pattern, but are related to general dietary pattern variance that is common across life periods.

Given that lifetime exposures, including diet, contribute to older-age health outcomes, it was also of interest, for explora- tory purposes, to investigate the associations between recalled lifetime dietary patterns and the specific markers of cardiovascular health that were measured in this cohort. Although it is well established that dietary intake has an impact on cardiovascular outcomes in later life ${ }^{(16,67)}$, there is only scant evidence from longitudinal cohort studies as to the contribution of earlier-life dietary influences on long-term outcomes. In the Boyd Orr cohort ${ }^{(68)}$, the association was examined between household diet during childhood and cardiovascular-induced death post- 30 and -50 years of age. A higher consumption of fruit and vegetables but a lower consumption of fish was associated with lower stroke risk. These authors did not propose a mechanism for the fruit and vegetable association with later stroke risk, but suggested that the finding may have been due to confounding and should be reproduced ${ }^{(69)}$. Higher HDL levels are protective against the risk of stroke ${ }^{(70)}$, and healthy levels are partly determined by the dietary intake of fruit and vegetables ${ }^{(71)}$. The childhood 'traditional Australian' pattern in the present study predicted higher HDL levels and is a pattern primarily defined by higher loadings from both fruit and vegetables. It is possible that frequent consumption of these items during childhood may determine a lifetime of habitual intake, thereby lowering the risk of unfavourable vascular outcomes via HDL maintenance.

Consumption of this childhood 'traditional Australian' pattern was also associated (at borderline significance, $P=0.05)$ with participants having lower systolic blood pressure. This finding adds support to the increasing evidence that early-life factors, including childhood diet, are important determinants of later-life hypertensive outcomes ${ }^{(72)}$. The pattern is defined by factor loadings from spinach, tomatoes, pumpkin, nuts and eggs, all of which are high in vitamin $\mathrm{E}^{(73)}$. Relationships between vitamin $\mathrm{E}$ intake from food in childhood and cardiovascular health in mid-life were examined in the 1946 British birth cohort ${ }^{(74)}$. No associations were found for the effect of intake during either childhood or middle age alone, but the lowest consumers of vitamin $\mathrm{E}$ 
in childhood, together with low intake at 43 years, were more likely to be hypertensive ${ }^{(74)}$. An additional explanation for the protective effect of the childhood 'traditional Australian' diet on later-life blood pressure measurement is via the $\mathrm{K}$ content of other higher-loading foods such as apricots, bananas, citrus, melon, figs, nuts, tomatoes and pears ${ }^{(73,75)}$.

Borderline significance $(P=0.05)$ was also found for the prediction of higher diastolic blood pressure by greater consumption of the 'vegetable' pattern in the early adulthood period. The association between diastolic blood pressure and cardiovascular risk is not clear-cut in older adults, and there is some evidence that higher diastolic blood pressure may actually be protective in this age group ${ }^{(76,77)}$.

In contrast to the protective effects of the fruit- and vegetablebased diets, those high in trans-fats or foods with a high glycaemic index are detrimental to cardiovascular health. The 20-year follow-up of the Nurses' Study cohort $^{(78)}$ has demonstrated that in 78778 women free of CHD in 1980, trans-fat intake significantly increased the odds of disease development particularly in younger or overweight women. In the present study, a higher consumption of such a pattern (processed, high-sugar and high-fat) in adulthood was associated with lower levels of HDL-cholesterol in older age. Just as high HDL levels are protective, lower HDL levels are considered a risk factor for CVD via their contribution to the atherosclerotic process, which, from early onset, takes many decades to develop the lesions that result in heart disease ${ }^{(79)}$.

One other lifetime dietary pattern predicted cardiovascular health in the EPOCH cohort. Current cardiac medication use was negatively associated with the 'non-traditional Australian' pattern in adulthood, a pattern similar in many respects to a Mediterranean-style diet. It is defined by herbs, parsley, red and white wine, yogurt, olive oil, seafood, chicken and whole grains. Given the empirical findings regarding the protective effect of such a diet in adulthood on later cardiac health $^{(80)}$, the association between this recalled dietary pattern and the non-use of medications for cardiac conditions further contributes to establishing the validity of the LDQ.

\section{Conclusions}

This is the first known study to extract retrospective dietary patterns from across periods comprising an individual's whole life. Although precise estimates of intake over such a timeframe are impossible, the present exploratory analyses have demonstrated the utility of a simplified, non-quantitative approach to gathering long-term food frequency data from older cognitively healthy people.

Building on these findings by replication is desirable. Doing so potentially provides valuable public health information regarding dietary modifications that are possible in earlierlife periods so as to increase the odds of a healthier older age. Although it is acknowledged that error in recalled historical diet is an inevitable outcome of such an approach, as is some confounding by unmeasured environmental factors, it nonetheless offers a valuable and hitherto untapped contribution to unravelling the influence of early-life dietary choices on older-age health when long-term dietary information is otherwise not available.

\section{Acknowledgements}

The present study was supported by an NHMRC project grant (no. 578800) and the Brailsford Robertson Award (University of Adelaide and CSIRO Food and Nutritional Sciences) awarded to V. D. D. H. was supported by a PhD scholarship jointly funded by the Faculty of Health Science at the University of Adelaide, South Australia, and CSIRO Food and Nutritional Sciences. We thank the participants of the EPOCH trial for their participation. D. H. was responsible for the concept and design of the study, collected the lifetime dietary data, conducted the statistical analyses and wrote the manuscript. V. D. was responsible for the concept and design of the EPOCH trial and of the present study, statistical analyses and manuscript revision and approved the final version. Neither of the authors has a conflict of interest.

\section{References}

1. World Health Organization (2002) Active Ageing: A Policy Framework. Report. Geneva: World Health Organization.

2. Darnton-Hill I, Nishida C \& James W (2004) A life course approach to diet, nutrition and the prevention of chronic diseases. Public Health Nutr 7, 101-121.

3. Ben-Shlomo Y \& Kuh D (2002) A life course approach to chronic disease epidemiology: conceptual models, empirical challenges and interdisciplinary perspectives. Int J Epidemiol 31, 285-293.

4. NHMRC (2009) Nutrient reference values for Australia and New Zealand. http://www.nrv.gov.au/disease/introduction. htm

5. Hu FB (2002) Dietary pattern analysis: a new direction in nutritional epidemiology. Curr Opin Lipidol 13, 3-9.

6. Kant AK (2004) Dietary patterns and health outcomes. J Am Diet Assoc 104, 615-635.

7. Newby PK \& Tucker KL (2004) Empirically derived eating patterns using factor or cluster analysis: a review. Nutr Rev 62, 177-203.

8. Kennedy ET, Ohls J, Carlson S, et al. (1995) The healthy eating index: design and applications. J Am Diet Assoc 95 1103-1108.

9. Trichopoulou A, Costacou T, Bamia C, et al. (2003) Adherence to a Mediterranean diet and survival in a Greek population. $N$ Engl J Med 348, 2599-2608.

10. Moeller SM, Reedy J, Millen AE, et al. (2007) Dietary patterns: challenges and opportunities in dietary patterns research: an Experimental Biology workshop, April 1, 2006. J Am Diet Assoc 107, 1233-1239.

11. Martínez ME, Marshall JR \& Sechrest L (1998) Invited Commentary: factor analysis and the search for objectivity. $\mathrm{Am}$ J Epidemiol 148, 17-19.

12. Schulze MB \& Hoffmann K (2006) Methodological approaches to study dietary patterns in relation to risk of coronary heart disease and stroke. Br J Nutr 95, 860-869.

13. Slattery ML \& Boucher KM (1998) The senior authors' response: factor analysis as a tool for evaluating eating patterns. Am J Epidemiol 148, 20-21.

14. Weikert C, Hoffmann K, Dierkes J, et al. (2005) A homocysteine metabolism-related dietary pattern and the risk of 
coronary heart disease in two independent German study populations. J Nutr 135, 1981-1988.

15. van Dam RM, Grievink L, Ocke MC, et al. (2003) Patterns of food consumption and risk factors for cardiovascular disease in the general Dutch population. Am J Clin Nutr 77, $1156-1163$.

16. Tourlouki E, Matalas A-L \& Panagiotakos DB (2009) Dietary habits and cardiovascular disease risk in middle-aged and elderly populations: a review of evidence. Clin Interv Aging 4, 319-330.

17. Murtaugh MA, Sweeney C, Giuliano AR, et al. (2008) Diet patterns and breast cancer risk in Hispanic and non-Hispanic white women: the Four-Corners Breast Cancer Study. Am J Clin Nutr 87, 978-984.

18. Schulze MB, Hoffmann K, Manson JE, et al. (2005) Dietary pattern, inflammation, and incidence of type 2 diabetes in women. Am J Clin Nutr 82, 675-684.

19. Kim HS, Park SY, Grandinetti A, et al. (2008) Major dietary patterns, ethnicity, and prevalence of type 2 diabetes in rural Hawaii. Nutrition 24, 1065-1072.

20. Barberger-Gateau P, Raffaitin C, Letenneur L, et al. (2007) Dietary patterns and risk of dementia: the Three City Cohort Study. Neurology 69, 1921-1930.

21. Akbaraly TN, Singh-Manoux A, Marmot MG, et al. (2009) Education attenuates the association between dietary patterns and cognition. Dement Geriatr $\operatorname{Cogn}$ Disord 27, $147-154$.

22. Huijbregts P, Feskens E, Rasanen L, et al. (1997) Dietary pattern and 20 year mortality in elderly men in Finland, Italy, and the Netherlands: Longitudinal Cohort Study. BMJ 315, 13-17.

23. Brunner EJ, Mosdol A, Witte DR, et al. (2008) Dietary patterns and $15-y$ risks of major coronary events, diabetes, and mortality. Am J Clin Nutr 87, 1414-1421.

24. Trichopoulos D \& Lagiou P (2001) Dietary patterns and mortality. Br J Nutr 85, 133-134.

25. Heroux M, Janssen I, Lam M, et al. (2010) Dietary patterns and the risk of mortality: impact of cardiorespiratory fitness. Int J Epidemiol 39, 197-209.

26. Darmon N \& Drewnowski A (2008) Does social class predict diet quality? Am J Clin Nutr 87, 1107-1117.

27. Mishra GD, McNaughton SA, Ball K, et al. (2010) Major dietary patterns of young and middle aged women: results from a prospective Australian cohort study. Eur J Clin Nutr $6 \mathbf{4}$, 1125-1133.

28. Park S-Y, Murphy SP, Wilkens LR, et al. (2005) Dietary patterns using the food guide pyramid groups are associated with sociodemographic and lifestyle factors: the Multiethnic Cohort Study. J Nutr 135, 843-849.

29. Mishra G, Ball K, Arbuckle J, et al. (2002) Dietary patterns of Australian adults and their association with socioeconomic status: results from the 1995 National Nutrition Survey. Eur J Clin Nutr 56, 687-693.

30. Whalley LJ, Dick FD \& McNeill G (2006) A life-course approach to the aetiology of late-onset dementias. Lancet Neurol 5, 87-96.

31. Wadsworth MEJ, Butterworth SL, Hardy RJ, et al. (2003) The life course prospective design: an example of benefits and problems associated with study longevity. Soc Sci Med 57, 2193-2205.

32. Hosking D, Danthiir V, Nettelbeck T, et al. (2011) Assessing lifetime diet: reproducibility of a self-administered, nonquantitative FFQ. Public Heath Nutr 14, 801-808.

33. Friedenreich CM, Slimani N \& Riboli E (1992) Measurement of past diet: review of previous and proposed methods. Epidemiol Rev 14, 177-196.
34. Dwyer JT \& Coleman K (1997) Insights into dietary recall from a longitudinal study: accuracy over four decades. $\mathrm{Am}$ J Clin Nutr 65, Suppl., 1153S-1158S.

35. Danthiir V, Burns NR, Nettelbeck T, et al. (2011) The Older People, Omega-3, and Cognitive Health (EPOCH) trial design and methodology: a randomised, double-blind, controlled trial investigating the effect of long-chain omega-3 fatty acids on cognitive ageing and wellbeing in cognitively healthy older adults. Nutr J 10, 1-36.

36. AIHW (2007) Older Australia at a Glance, 4th ed. Canberra: Australian Institute of Health and Welfare.

37. Folstein MF, Folstein SE \& McHugh PR (1975) Mini-mental state. J Psychiatr Res 12, 189-198.

38. Giles GG \& Ireland PD (1996) Dietary Questionnaire for Epidemiological Studies (Version 2). Melbourne: Cancer Council Victoria.

39. Dwyer JT, Gardner J, Halvorsen K, et al. (1989) Memory of food intake in the distant past. Am J Epidemiol 130, 1033-1046.

40. Fraser GE, Yan R, Butler TL, et al. (2009) Missing data in a long food frequency questionnaire: are imputed zeroes correct? Epidemiology 20, 289-294.

41. Michels KB \& Willett WC (2009) Self-administered semiquantitative food frequency questionnaires: patterns, predictors, and interpretation of omitted items. Epidemiology 20, 295-301.

42. Uebersax JS (2006) Introduction to the tetrachoric and polychoric correlation coefficients. http://john-uebersax.com/ stat/tetra.htm

43. Kline P (1994) An Easy Guide to Factor Analysis. London: Routledge.

44. Fabrigar LR, Wegener DT, MacCallum RC, et al. (1999) Evaluating the use of exploratory factor analysis in psychological research. Psychol Methods 4, 272-299.

45. Stellefson ML, Hanik BW, Chaney BH, et al. (2009) Factor retention in EFA: strategies for health behavior researchers. Am J Health Behav 33, 587-599.

46. Costello AB \& Osborne JW (2005) Best practices in exploratory factor analysis: four recommendations for getting the most from your analysis? Pract Assess Res Eval 10, 1-9.

47. DiStefano C, Zhu M \& Mîndrilă D (2009) Understanding and using factor scores: considerations for the applied researcher. Pract Assess Res Eval 14, 1-7.

48. Green SB (1991) How many subjects does it take to do a regression analysis? Multivariate Behav Res 26, 499.

49. Myers RH (1990) Classical and Modern Regression with Applications. Boston, MA: Duxbury.

50. Tabachnick BG \& Fidell LS (2007) Using Multivariate Statistics, 5th ed. Sydney: Pearson Education Inc.

51. Peduzzi P, Concato J, Kemper E, et al. (1996) A simulation study of the number of events per variable in logistic regression analysis. J Clin Epidemiol 49, 1373-1379.

52. Truswell AS \& Wahlqvist ML (1988) Food Habits in Australia: The First Deakin/Syndey Universities Symposium on Australian Nutrition, 1st ed. North Balwyn: Rene Gordon Pty Ltd.

53. Lake AA, Rugg-Gunn AJ, Hyland RM, et al. (2004) Longitudinal dietary change from adolescence to adulthood: perceptions, attributions and evidence. Appetite $\mathbf{4 2}$, 255-263.

54. Weismayer C, Anderson JG \& Wolk A (2006) Changes in the stability of dietary patterns in a study of middle-aged Swedish women. J Nutr 136, 1582-1587.

55. Mishra GD, McNaughton SA, Bramwell GD, et al. (2006) Longitudinal changes in dietary patterns during adult life. Br J Nutr 96, 735-744. 
56. Mishra GD, Prynne CJ, Paul AA, et al. (2004) The impact of inter-generational social and regional circumstances on dietary intake patterns of British adults: results from the 1946 British birth cohort. Public Health Nutr 7, 737-744.

57. Pryer JA, Nichols R, Elliott P, et al. (2001) Dietary patterns among a national random sample of British adults. $J$ Epidemiol Community Health 55, 29-37.

58. Wendt M, Kinsey J (2007) Do Eating Patterns Follow a Cohort or Change Over a Lifetime? Answers Emerging from the Literature. Minneapolis: The Food Industry Center, University of Minnesota.

59. Villegas R, Salim A, Collins MM, et al. (2004) Dietary patterns in middle-aged Irish men and women defined by cluster analysis. Public Health Nutr 7, 1017-1024.

60. Vlismas K, Stavrinos V \& Panagiotakos DB (2009) Socioeconomic status, dietary habits and health-related outcomes in various parts the world: a review. Cent Eur J Public Health 17, 55-63.

61. Mullie P, Clarys P, Hulens M, et al. (2010) Dietary patterns and socioeconomic position. Eur J Clin Nutr 64, 231-238.

62. De Irala-Estévez J, Groth M, Johansson L, et al. (2000) A systematic review of socio-economic differences in food habits in Europe: consumption of fruit and vegetables. Eur J Clin Nutr 54, 706-714

63. World Health Organization (2004) Global Strategy on Diet, Physical Activity and Health: The Americas Regional Consultation Meeting Report. San Jose: World Health Organization.

64. La Vecchia C, Negri E, Franceschi S, et al. (1992) Differences in dietary intake with smoking, alcohol, and education. Nutr Cancer 17, 297-304.

65. Whichelow MJ \& Prevost AT (1996) Dietary patterns and their associations with demographic, lifestyle and health variables in a random sample of British adults. Br J Nutr 76, 17-30.

66. O'Doherty MG, Skidmore PM, Young IS, et al. (2011) Dietary patterns and smoking in northern Irish men: a population at high risk of coronary heart disease. Int J Vitam Nutr Res $\mathbf{8 1}$, $21-33$.

67. Mente A, de Koning L, Shannon HS, et al. (2009) A systematic review of the evidence supporting a causal link between dietary factors and coronary heart disease. Arch Intern Med 169, 659-669.
68. Martin RM, Gunnell D, Pemberton J, et al. (2005) Cohort profile: the Boyd Orr cohort - an historical cohort study based on the 65 year follow-up of the Carnegie survey of diet and health (1937-1939). Int J Epidemiol 34, 742-749.

69. Ness AR, Maynard M, Frankel S, et al. (2005) Diet in childhood and adult cardiovascular and all cause mortality: the Boyd Orr cohort. Heart 91, 894-898.

70. Boden-Albala B, Sacco RL, Lee H-S, et al. (2008) Metabolic syndrome and ischemic stroke risk: Northern Manhattan study. Stroke 39, 30-35.

71. Bertsias G, Linardakis M, Mammas I, et al. (2005) Fruit and vegetables consumption in relation to health and diet of medical students in Crete, Greece. Int J Vitam Nutr Res $\mathbf{7 5}$, 107.

72. Lawlor DA \& Smith GD (2005) Early life determinants of adult blood pressure. Curr Opin Nephrol Hypertens 14, 259-264.

73. United States Department of Agriculture (2011) National Nutrient Database for Standard Reference, release 24. http://www.ars.usda.gov/nutrientdata (accessed 5 March 2013).

74. Mishra GD, Malik NS, Paul AA, et al. (2003) Childhood and adult dietary vitamin $\mathrm{E}$ intake and cardiovascular risk factors in mid-life in the 1946 British Birth cohort. Eur J Clin Nutr 57, 1418-1425.

75. He J \& Whelton PK (1997) Potassium, blood pressure, and cardiovascular disease: an epidemiologic perspective. Cardiol Rev 5, 255-260.

76. Okayama A, Kadowaki T, Okamura T, et al. (2006) Agespecific effects of systolic and diastolic blood pressures on mortality due to cardiovascular diseases among Japanese men. J Hypertens 24, 459-462.

77. Basile JN (2002) Systolic blood pressure. Br Med J 325, 917-918.

78. Oh K, Hu FB, Manson JE, et al. (2005) Dietary fat intake and risk of coronary heart disease in women: 20 years of followup of the Nurses' Health study. Am J Epidemiol 161, 672-679.

79. Hansson GK, Robertson A-KL \& Söderberg-Nauclér C (2006) Inflammation and atherosclerosis. Annu Rev Pathol 1, 297-329.

80. Willett WC (2006) The Mediterranean diet: science and practice. Public Health Nutr 9, 105-110. 